Saudi Journal of Pathology and Microbiology

Abbreviated Key Title: Saudi J Pathol Microbiol

ISSN 2518-3362 (Print) |ISSN 2518-3370 (Online)

Scholars Middle East Publishers, Dubai, United Arab Emirates

Journal homepage: http://scholarsmepub.com/sjpm/

Original Research Article

\title{
Hydatid Disease in the Western Region of Saudi Arabia, A University Medical Center Experience
}

\author{
Fahad A Alghamdi* \\ Department of pathology, College of Medicine, King Abdulaziz University, Jeddah, Saudi Arabia
}

DOI: 1 10.36348/SJPM.2019.v04i10.010 $\quad$ | Received: 21.10.2019| Accepted: 28.10 .2019 | Published: 30.10 .2019

*Corresponding author: Fahad A Alghamdi

Abstract

Hydatid disease (HD) is a zoonotic infection caused by larval stage of Echinococcus granulosus. It is a worldwide health problem causing significant socio-economic impact. This retrospective study included 19 patients diagnosed with HD at a university medical center between 2007 and 2019 in Western Region of Saudi Arabia. There were 68\% (n=13) males and $32 \%(n=6)$ females (mean age $40 \pm 17$ years). The clinical presentations were variable and non-specific. The affected organs were as follows: liver (68\%), lung (32\%), soft tissue (11\%), peritoneal nodule (5\%), kidney $(5 \%)$, and brain $(5 \%)$. Multiple organ involvement and combined liver and lung were seen in $26 \%(\mathrm{n}=5)$ and $16 \%(\mathrm{n}=3)$ of the patients, respectively. The mean diameter of cyst was $8.98 \pm 1.77 \mathrm{~cm}$. Serology confirmatory test was positive in $95 \%(\mathrm{n}=18)$ of the patients. Blood eosinophilia was noticed in $32 \%(n=6)$ of the patients. Histopathological and cytological features include laminated cyst wall, inner germinal layer and protoscolices. Management included cyst resection or PAIR (Puncture, Aspiration, Injection of protoscolicidal agent and Re-aspiration) technique combined with anthelmintic drugs. The overall recurrence rate was $7.5 \%$ and $60 \%$ for surgery and PAIR, respectively. Overall mortality rate was $0 \%$. In conclusion, considering that there is no pathognomonic clinical feature for $\mathrm{HD}$, it may lead to confusion and delaying in diagnosis. Good history including exposure to dogs in the endemic areas, good imaging modalities and the proper use of serology might help for suspecting HD. The histopathological findings are valuable in confirming diagnosis of HD.

Keywords: Hydatid disease, Echinococcus granulosus, zoonotic, liver, lung, PAIR.

Copyright @ 2019: This is an open-access article distributed under the terms of the Creative Commons Attribution license which permits unrestricted use, distribution, and reproduction in any medium for non-commercial use (NonCommercial, or CC-BY-NC) provided the original author and sources are credited.

\section{INTRODUCTION}

Hydatid disease (HD) is a zoonotic infectious disease caused by the larval stage of tapeworm Echinococcus granulosus. The adult tapeworm lives in the small intestine of dogs, which are most important definitive host. The gravid proglottids pass in the feces and rupture releasing eggs that swallowed by the sheep (the most common intermediate host) [1, 2]. Human could become an accidental intermediate host when he comes in contact with infected definite host (e.g. children carry ova in their hands when they have play with Dog's fur), or ingests contaminated food or water with infected animal feces [2,3]. The hatched eggs penetrate the intestinal mucosa to the blood stream forming hydatid cysts in different organs. Liver, followed by lung, is the most common site of hydatid cyst. However, other less common anatomic locations have been reported $[1,2,4]$.

Clinical presentation of HD is variable and not specific. $\mathrm{HD}$ is diagnosed by serological assays, radiological assessment, and histopathological and cytological examinations. Histopathological and cytological findings include laminated cyst wall, protoscolices and variable host-response reactions in the form of fibrosis and mixed inflammatory infiltrate [4].

Hydatid disease is a worldwide health issue, particularly common in cattle rearing areas. It has considerable mortality, morbidity and socio-economic impact in many developing countries. It is one of the neglected zoonotic diseases (NZDs) according to WHO [5]. As far as we know, the prevalence of HD in Saudi Arabia is not yet reported. There are some published reports about HD in Saudi Arabia [6, 7, 8]; however, none of them have evaluated the burden of this disease in Western region of Saudi Arabia. The aim of this study is to evaluate the demographic, clinical, and pathological features including organ distribution, treatment options and outcome on this neglected zoonotic disease (NZDs) in the western region of Saudi Arabia. 


\section{MATERIAL AND METHODS}

This retrospective study was conducted in the department of Pathology at King Abdulaziz University Hospital (1067-bedded tertiary care and academic hospital at Western region of Saudi Arabia) between 2007-2019. The study included nineteen cases diagnosed as hydatid disease in this certain period. Clinical data of the patients were retrieved from the hospital records. Formalin fixed, paraffin-embedded samples were cut into 5 microns and stained with Hematoxylin and Eosin (H\&E). Cytology specimens were prepared from the aspirate of six cases, fixed in absolute alcohol and stained by Papanicolau and diff quick stains. The slides were reviewed by the same pathologist. The criteria for diagnosis include hydatid membranes, protoscolices and hooklets.

We evaluated the following (a) the demographic features (b) the clinical presentations (c) the anatomic location, size and number of cysts, and multiple organ involvement (d) some laboratory features including the presence of eosinophilia and positivity for serologic test (IHA test) (e) the histopathological and cytological findings including outer acellular laminated membrane, the inner germinal membrane, protoscolices, and host-response reactions (f) the treatment modalities and ( $\mathrm{g}$ ) the outcome.

\section{RESULTS}

In this study, there were $13(68 \%)$ male and 6 $(32 \%)$ female patients. The age ranges between 13 and 75 years (mean age was $40 \pm 17$ years). Most of the patients were in peak age group of 25-50 years (Table1). Among this sample, there were two patients with recent contact with dogs; however, data of history in contact with animal for other patients was not clarified in patient's files.

Table-1: Age and Sex Distribution among 19 patients.

\begin{tabular}{|c|c|c|c|}
\hline Age & Male & Female & Total \\
\hline Mean \pm standard deviation & $37 \pm 12$ & $45 \pm 22$ & $40 \pm 17$ \\
\hline$<25$ & 2 & 1 & 3 \\
\hline $25-50$ & 9 & 2 & 11 \\
\hline$>50$ & 2 & 3 & 5 \\
\hline Total & 13 & 6 & 19 \\
\hline
\end{tabular}

The most frequent clinical manifestations were from hepatic, lung, brain and soft tissue involvement and including abdominal pain (58\%), fever (21\%), cough $(16 \%)$, shortness of breath $(16 \%)$, hemoptysis (11\%), soft tissue palpable mass $(11 \%)$, obstructive jaundice $(5 \%)$, and convulsion (5\%). Other clinical complications included lung empyema in one patient and communication of liver HD cyst with common bile duct in another two patients; one of them complained of passing worms in stool.
The affected organs by of cysts: liver $(\mathrm{n}=13$; $68 \%)$, lung $(n=6 ; 32 \%)$, soft tissue $(n=2 ; 11 \%)$, peritoneal nodule $(\mathrm{n}=1 ; 5 \%)$, kidney $(\mathrm{n}=1 ; 5 \%)$, and brain $(n=1 ; 5 \%)$. Multiple organ involvement was seen in 5 patients $(26 \%)$, three of them had combined liver and lung involvement (16\%). Other multiple organ involvement demonstrated in (Table-2). The mean diameter of cysts was $8.98 \pm 1.77 \mathrm{~cm}$ and ranged between $1 \mathrm{~cm}$ and $13 \mathrm{~cm}$. The number of cysts per organ and average diameter of each cyst were illustrated in (Table-3).

Table-2: Single versus multiple organ involvement

\begin{tabular}{|c|c|c|c|}
\hline & Male & Female & Total \\
\hline Cyst location & $\mathbf{n}(\boldsymbol{\%})$ & $\mathbf{n}(\mathbf{\%})$ & $\mathbf{n}(\boldsymbol{\%})$ \\
\hline A. Single organ involvement & $\mathbf{9 ( \sim 4 7 \% )}$ & $\mathbf{5 ( \sim 2 6 \% )}$ & $\mathbf{1 4}(\sim 74 \%)$ \\
\hline 1. Liver & $5(\sim 26 \%)$ & $3(\sim 16 \%)$ & $8(\sim 42 \%)$ \\
\hline 2. Lung & $3(\sim 16 \%)$ & $0(0 \%)$ & $3(\sim 16 \%)$ \\
\hline 3. Soft tissue & $0(0 \%)$ & $2(\sim 11 \%)$ & $2(\sim 11 \%)$ \\
\hline 4. Brain & $1(\sim 5 \%)$ & $0(0 \%)$ & $1(\sim 5 \%)$ \\
\hline B. Multiple organ involvement & $\mathbf{4 ( \sim 2 1 \% )}$ & $\mathbf{1 ( \sim 5 \% )}$ & $\mathbf{5 ( \sim 2 6 \% )}$ \\
\hline 1. Liver and lung & $2(\sim 11 \%)$ & $1(\sim 5 \%)$ & $3(\sim 16 \%)$ \\
\hline 2. Liver and kidney & $1(\sim 5 \%)$ & $0(0 \%)$ & $1(\sim 5 \%)$ \\
\hline 3. Liver and peritoneum & $1(\sim 5 \%)$ & $0(0 \%)$ & $1(\sim 5 \%)$ \\
\hline
\end{tabular}


Table-3: The number of cysts per organ and average diameter among 19 cases

\begin{tabular}{|c|c|c|c|c|}
\hline $\begin{array}{c}\text { Number of } \\
\text { cysts with: }\end{array}$ & $\begin{array}{c}\text { One cyst/ organ } \\
\text { (Average size) }\end{array}$ & $\begin{array}{c}\text { 2 cysts/ organ } \\
\text { (average size) }\end{array}$ & $\begin{array}{c}\text { 3 or more cysts/ organ } \\
\text { (average size) }\end{array}$ & $\begin{array}{c}\text { Total mean } \\
\text { diameter } \pm \text { SD }\end{array}$ \\
\hline Liver & $9(11 \mathrm{~cm})$ & $1(13 \mathrm{~cm})$ & $3(7 \mathrm{~cm})$ & $10.2 \pm 1.85 \mathrm{~cm}$ \\
\hline Lung & $4(10 \mathrm{~cm})$ & $1(10 \mathrm{~cm})$ & $1(7.6 \mathrm{~cm})$ & $9.6 \pm 0.98 \mathrm{~cm}$ \\
\hline Soft tissue & $2(7 \mathrm{~cm})$ & 0 & 0 & $7 \pm 0 \mathrm{~cm}$ \\
\hline Brain & 0 & 0 & $1(5 \mathrm{~cm})$ & $5 \pm 0 \mathrm{~cm}$ \\
\hline Kidney & $1(5 \mathrm{~cm})$ & 0 & 0 & $5 \pm 0 \mathrm{~cm}$ \\
\hline Peritoneal & $1(1 \mathrm{~cm})$ & 0 & $6.72 \pm 0.95 \mathrm{~cm}$ & $8.98 \pm 1.77 \mathrm{~cm}$ \\
\hline $\begin{array}{c}\text { Mean diameter } \\
\pm \text { SD }\end{array}$ & $9.35 \pm 2.31 \mathrm{~cm}$ & $11.5 \pm 1.5 \mathrm{~cm}$ & & $1 \pm 0 \mathrm{~cm}$ \\
\hline
\end{tabular}

The antibody titers for echinococcosis using commercial available IHA test were positive in $95 \%$ $(\mathrm{n}=18)$ of the patients. The presence of blood eosinophilia was noticed in only $32 \%(n=6)$ of the patients. The histopathological findings of hydatid cysts included outer acellular laminated cyst wall, inner germinal membrane and protoscolices containing multiple hooklets (Figure 1A-D). While outer acellular laminated membrane was seen in all cases $(100 \%)$, the protoscolices were identified only in 12 cases $(63 \%$ of the patient); and three of them were degenerated protoscolices (16\%). Other findings include calcification in cyst wall. The cysts were surround by host reaction responses including fibrosis (figure 1-A), inflammatory infiltrate containing eosinophils, plasma cells, lymphocytes, histiocytes and foreign-body type granulomatous reaction (Figure 1-B). Cytological assessment of FNA samples showed many protoscolices with refractile hooklets, dispersed floater hooklets (Figure-2), parts of laminated membrane, granular debris and mixed inflammatory cells.

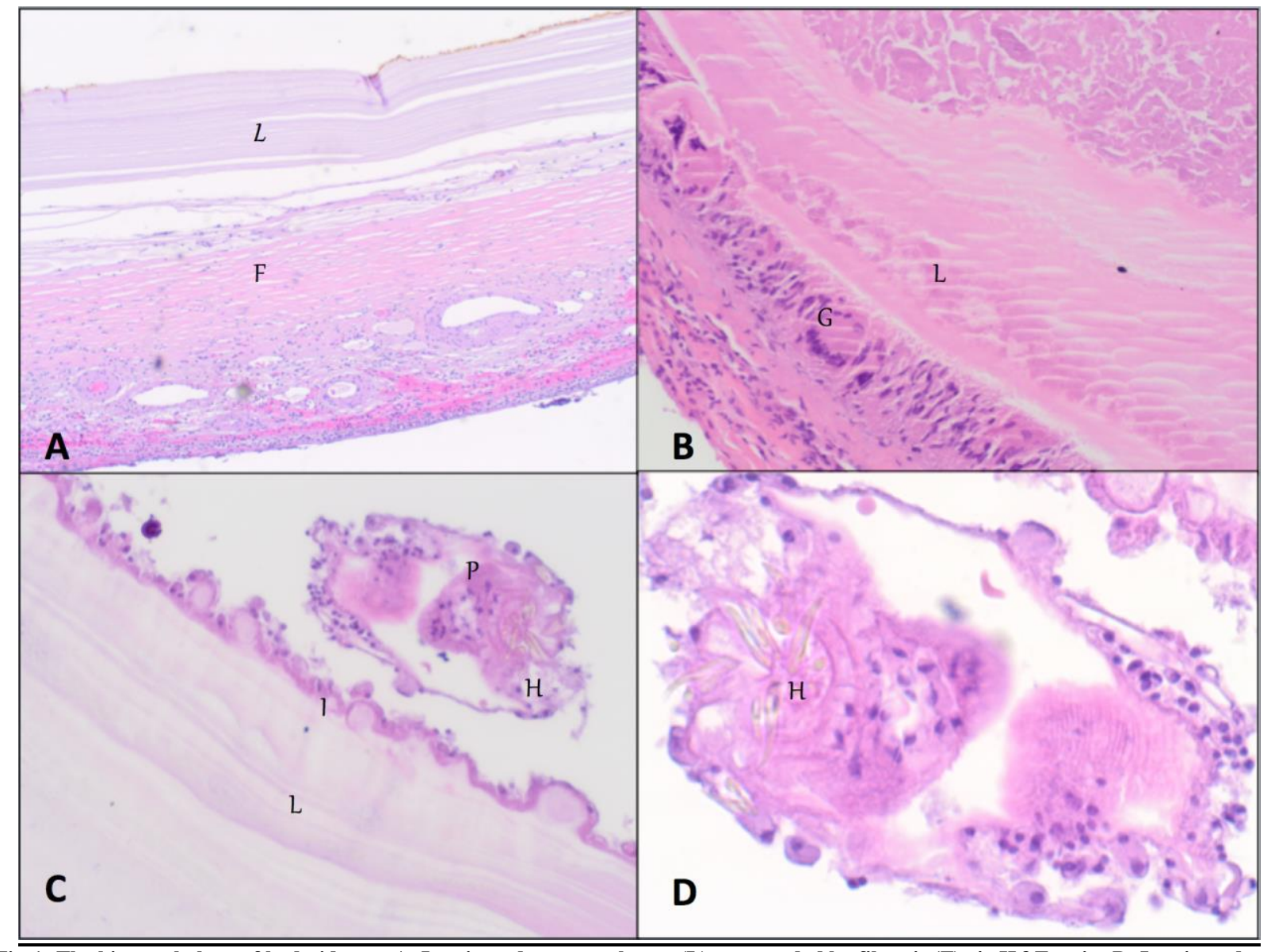

Fig-1: The histopathology of hydatid cyst: A: Laminated cyst membrane (L) surrounded by fibrosis (F), 4x H\&E stain. B: Laminated cyst membrane (L) surrounded by foreign-body type giant cell reaction (G), 20x H\&E stain. C: Laminated cyst membrane (L), inner germinal layer (I), and protoscolex $(\mathrm{P})$ containing refractile yellow to golden hooklets $(\mathrm{H}), 20 x \mathrm{H} \& \mathrm{E}$ stain. D: High power of protoscolex containing refractile yellow to golden hooklets $(\mathrm{H}), 40 x \mathrm{H} \& \mathrm{E}$ stain 


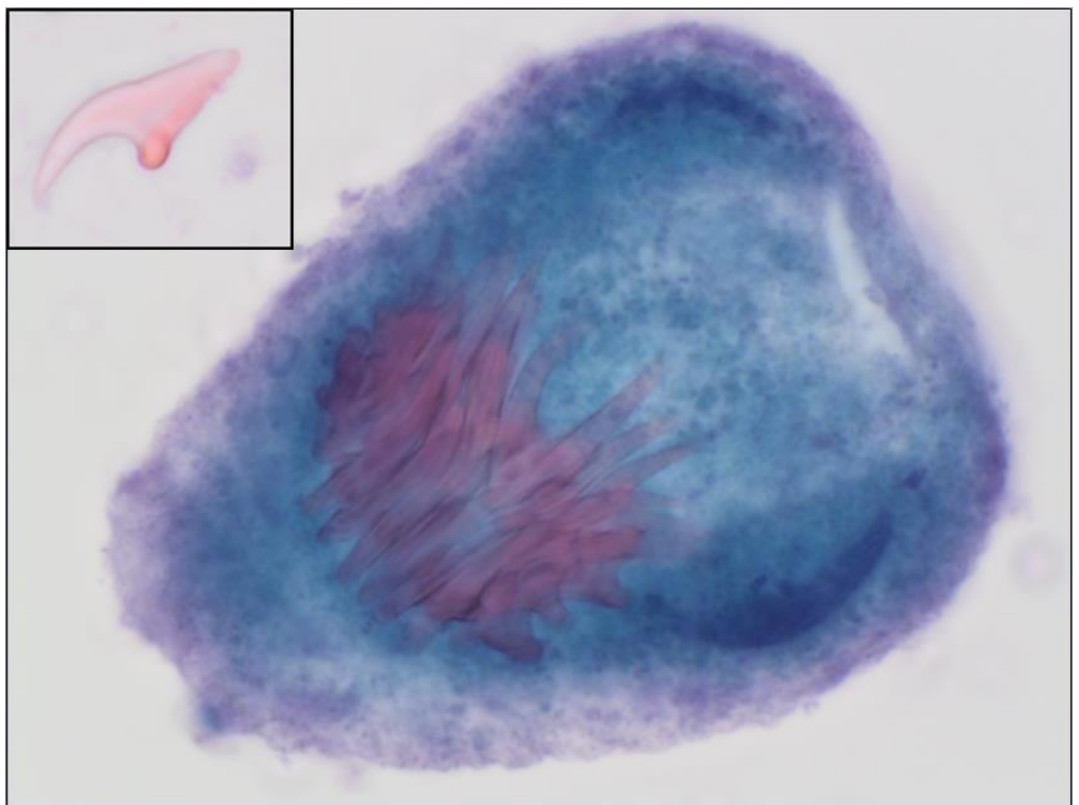

Fig-2: FNA cytology of hydatid cyst from external oblique muscle cyst: Protoscolex containing many refractile hooklets (Pap stain, 65x), Inset: floater hooklet (Pap stain, $40 \mathrm{x}$ )

Seventeen patients $(89.5 \%)$ were treated by combination of cyst resection or PAIR and pre- and post-operation anthelmintic drug (albendazole $400 \mathrm{mg}$ ) for variable duration (ranged from 4-20 weeks). Thirteen patients $(\sim 68 \%)$ of this group (included one patient that had failed PAIR approach) had been treated with surgical resection of cyst/s (modality 1, Table-6) and five patients $(26 \%)$ had been treated by PAIR technique (modality 2, Table-6).

The remaining two female patients (10.5\%) have been presented with cysts that were not suspected initially to be HD. The first one had presented with simple liver cyst but her serology test for echinococcus antibody was negative. The other patient had history of multiple pregnancies with cesarean sections. She was presented with right external oblique muscle cyst, which has been thought clinically to be hematoma or endometriosis. The cysts in both cases have been aspirated (modality 3, Table-6). Cytology assessment of aspirated fluids showed few protoscolices, parts of laminated wall and floater hooklets (Figure-2). After establishing the diagnosis, the patients have been started on albendazole for a long course (12 wks - 20 wks).

In this study, no patient developed postsurgery or post-PAIR anaphylactic shock. The recurrence rate of modalities 1,2 , and 3 were $7.5 \%$, $60 \%$, and $50 \%$, respectively. The patient of recurring cyst in modality 1 had history of discontinuing albendazole by herself one week post-operation. One out of five cases treated by PAIR technique revealed a residual small cyst that showed no progression with time. The overall recurrence rate is $32 \%$ while the overall mortality for all cases was $0 \%$ (Table-4).

Table-4: The outcome of 19 patients according to the treatment modality

\begin{tabular}{|c|c|c|c|c|c|c|}
\hline \multirow{2}{*}{$\begin{array}{l}\text { Options of } \\
\text { treatment }\end{array}$} & \multirow[t]{2}{*}{ No $(\%)$} & & \multicolumn{4}{|c|}{ Outcomes } \\
\hline & & Cured & $\begin{array}{c}\text { Residual } \\
\text { stable cyst }\end{array}$ & Recurrent & $\begin{array}{l}\text { Loss of } \\
\text { follow up }\end{array}$ & $\begin{array}{c}\text { Mortality } \\
\text { Rate }\end{array}$ \\
\hline Modality 1 & $\begin{array}{l}12+1^{\mathrm{a}} \\
(68 \%)\end{array}$ & $\begin{array}{l}11 / 13 \\
(85 \%)\end{array}$ & $\begin{array}{l}0 / 13 \\
(0 \%)\end{array}$ & $\begin{array}{c}1 / 13 \\
(7.5 \%)\end{array}$ & $\begin{array}{c}1 / 13 \\
(7.5 \%)\end{array}$ & $(0 \%)$ \\
\hline Modality 2 & $\begin{array}{c}5 \\
(26 \%)\end{array}$ & $\begin{array}{c}1 / 5 \\
(20 \%)\end{array}$ & $\begin{array}{c}1 / 5 \\
(20 \%)\end{array}$ & $\begin{array}{c}3 / 5^{\mathrm{b}} \\
(60 \%)\end{array}$ & $\begin{array}{c}0 / 5 \\
(0 \%)\end{array}$ & $(0 \%)$ \\
\hline Modality 3 & $\begin{array}{c}2 \\
(10.5 \%)\end{array}$ & $\begin{array}{c}1 / 2 \\
\text { (muscle) } \\
(50 \%)\end{array}$ & $\begin{array}{c}0 / 2 \\
(0 \%)\end{array}$ & $\begin{array}{c}1 / 2 \text { (liver) } \\
(50 \%)\end{array}$ & $\begin{array}{c}0 / 2 \\
(0 \%)\end{array}$ & $(0 \%)$ \\
\hline Total & $19+1^{\mathrm{a}}$ & $\begin{array}{l}11+1^{\mathrm{a}} \\
(63 \%)\end{array}$ & $\begin{array}{c}1 \\
(5 \%)\end{array}$ & $\begin{array}{l}5+1^{b} \\
(32 \%)\end{array}$ & $\begin{array}{c}1 \\
(5 \%)\end{array}$ & $(0 \%)$ \\
\hline
\end{tabular}

: Included one case that failed modality 2.

b: One patient failed this modality and had been treated surgically.

Modality 1: Combination of surgery (cyst resection) + pre- and post-operation albendazole.

Modality 2: Combination of PAIR + pre- and post-technique albendazole.

Modality 3: Simple fluid aspiration of clinically non-suspected cyst, followed by albendazole 


\section{DISCUSSION}

Hydatid disease has a worldwide geographic distribution, particularly common in Mediterranean, Middle East, North and East Africa, Russia, China, India, South America, and Australasia [1, 4, 10, 11]. Ma et al., found a total of 7688 article publications on hydatid disease from 1980 to 2017. The largest numbers of published articles were from Turkey (1133 articles), followed by France (582 articles) and China (572 articles) [12]. The prevalence of hydatid disease in the Kingdom of Saudi Arabia and its variability from a region to another has not been reported [6]. However, few publications from Saudi Arabia have described individual experience in few hospitals. Malaika et al., described 188 cases of HD in various hospitals from different regions of Saudi Arabia [9]. While Alam and Fahim at el have reported total of 67 and 117 patients with HD over 10- and 5-years period, respectively in central region of Saudi Arabia [6, 7]. In another big hospital at south of Saudi Arabia, Jastaniah et al., have reported 43 patients with HD over a period of six-year [8]. There might be some variability of hydatid disease distribution among different areas of Saudi Arabia and that may be due to the difference in sociocultural and behavioral pattern of life and variability in the distribution of sheep-raising areas [6].

This study was carried out in western region of Saudi Arabia including a total 19 patients. The study showed a male predominance. A similar observation has been reported in two other studies from Saudi Arabia [6, 7]. The mean age of patients included in our study was $40 \pm 17$ years, and the peak age group was 25-50 years. While some reports from other countries like Turkey, Iran and India showed relatively similar peak age, the incidence was higher in females than males [6, 13-16]. Rao et al., have postulated that women are involved more than men in farming and herding livestock in their country; therefore women have more risk to get the disease [16]. The HD of human follows a relatively slow course. Patients might get the disease early in their life and stay asymptomatic for many years until the cysts become big enough to produce symptoms and complications in their middleage $[2,7]$. While patients start to have symptoms, unfortunately none of them are pathognomonic for HD [4]. This was also the case in this study, as the clinical presentations of the patients were variable, nonspecific, and represents more the affect of the enlarged cyst on surrounding tissue.

Imaging modalities are very helpful for suspecting HD disease. These modalities could help in identifying the avascular nature of the cyst, the present of daughter cysts, vesicles and internal septa [4]. The size of HD cyst might be highly variable [4]. Ettorre $e t$ $a l$, , reported a giant liver hydatid cyst with size of 30 $\mathrm{cm}$. When the size of HD cyst increases, the risk of perforation and subsequent anaphylaxis reaction is also increased. Therefore, radical therapy is recommended for giant cysts $[4,17]$. The size of hydatid cysts in our study was variable ranges from 1 to $13 \mathrm{~cm}$ (average diameter $8.98 \pm 1.77 \mathrm{~cm}$ ). Hydatid cysts of liver and lung were the largest (average diameter 10.2 and 9.6 $\mathrm{cm}$, respectively). Our study showed also multiple organ involvement in $26 \%$ of patients and the combination of liver and lung involvement was the highest $(n=3 ; 16 \%)$. In some published reports, multiple organ involvement was ranged from $7.1 \%$ to $12 \%[4,7$, $16]$, and combined liver and lung HD were in $10.0 \%$ [18], and $19.3 \%$ [19] of patients.

The majority of patients included in this study had HD of liver (68\%) while HD of lung was in the second place after liver (32\%). Unsurprisingly, this is consistent with many literature published reports $[1,6-$ $8,15,16]$. Not limited to liver and lung, our study revealed few other uncommon sites including abdominal external oblique muscle, soft tissue of thigh, peritoneal nodule, kidney and brain. Literatures review showed many other uncommon and rare locations like subcutaneous tissue [20], muscles [21-23], soft tissue [24], bone [25], pericardium [26], pleura [23], thyroid [27], gallbladder [4], spleen [4], uterus [28], ovary [3], breast [11], buccal mucosa [29], orbit [30], brain [11, 31], and spine [32]. The liver is the first effective filter for most of the larvae after it penetrated the intestinal mucosa; therefore liver is the most common site of HD. The lung is the second most frequently involved site if the larvae are able to pass through the first filter. If the larvae are not trapped in the first and second filters, they could travel to any part of the body. Other routes of spread might be though lymphatic circulation [4]. By knowing these routes of spread and variability in anatomic locations, HD should be considered as a differential diagnosis for any cystic lesion in a patient coming from an endemic area or having a history of contact with animal $[21,23]$.

The serological assays are currently used for screening, diagnosis, and post-surgery follow-up, however, its sensitivity is variable. In our study, it reached $94 \%$ (90\% for liver cysts and $100 \%$ for other organ cysts) while in other published studies; it was very high for liver cysts $(80-100 \%)$, low in lung (50$56 \%$ ) and other organs (25-56\%) [4]. Although HD is helminthic disease; eosinophilia was seen only in $32 \%$ of our cases. In most published cases, eosinophilia is either mild $(<15 \%)$ or absent, making eosinophilia of limited value in diagnosing HD. However, marked eosinophilia might indicate cyst rupture [7, 33].

The histological diagnosis of HD depends on the detection of the cyst wall and its contents. As the hydatid larva travels through blood circulation to its final destination, it becomes encysted. The fluid-filled cyst has spherical appearance and consists of an outer acidophilic-staining acellular laminated membrane and 
inner germinal layer. Small vesicles (called broad capsules) bud internally from the inner germinal layer and produce many protoscolices by asexual division [2]. These broad capsules may detach into the fluid of the cyst forming daughter cysts [2, 34]. The protoscolices are characterized with double row of acidfast hooklets that could be aspirated and detected in cytology specimens [35]. Host may react to the hydatid cyst by forming an outer layer of granulomatous reaction, mixed inflammatory infiltrate and fibrosis [2, 4]. Calcification of cyst wall might be seen in some cases [4]. Although fine needle aspiration cytology (FNAC) has an advantage of minimally invasive technique, low cost and high diagnostic accuracy; it was is encouraged for diagnosis of HD due to the possibility of spillage and subsequently causing anaphylactic reactions. On the other hand, Kammer and Schantz believed that the risk could be minimized if the procedure is guided by ultrasonography or computerized tomography [36, 37]. Mohamadnejad et $a l$., concluded that diagnostic FNAC could be done in equivocal cases with negative serological assays. They added that patients tolerated the FNA procedure well without any adverse events as it has been reported in many case reports [38]. Saha et al., recommended taking the necessary anti-anaphylactic measurement and special care to avoid the spread of protoscolices while doing FNAC procedure [39].

The choosing of treatment modalities depends on factors like the size and site of the cysts, health status of patient, and availability of these modalities in the treating hospital [4]. In general, the main effective treatment is total cyst resection without rupturing it. PAIR technique is another option. In a meta-analysis and systemic review of 33 studies, Velasco-Tirado et al showed that combination of cyst resection or PAIR and anthelmintic drugs give better outcomes [40]. The anthelmintic agents include mainly albendazole and praziquantel. Albendazole has the advantage of its ability to penetrate hydatid cyst wall and therefore it is recommended as first line medication. Praziquantel is more efficient but poor in penetrating cyst wall, therefore, it could be used in cases of ruptured cysts [4]. Watch and wait has been suggested for inactive and silent cysts [40].

The overall recurrence rate in our study was $32 \%$. Patients treated by surgical excision of whole cyst showed only $7.5 \%$ recurrence rate (only one patient). Although PAIR technique has advantage of minimally invasive approach, this technique had associated with $60 \%$ recurrence rate in our study. Few other studies showed that total surgical cyst excision is more curative and effective treatment than PAIR technique with similarity to our results $[4,41]$. The overall mortality rate in our study was $0 \%$. However, literature studies have reported higher mortality incidence reaching $3 \%$ in one study [4], and mortality rate of 3 per 100000 residents [42]. This might be attributed to the limited number in our study but it may also reflect the availability of different treatment modalities in our tertiary care hospital.

\section{CONCLUSION}

Despite of the fact that the HD are found most commonly in liver and lung; however, any organ could be affected by this neglected zoonotic tapeworm disease. Considering that there is no pathognomonic clinical feature for HD, it may lead to confusion and delaying in diagnosis. Good history including; exposure to dogs in the endemic areas, good imaging modalities and the proper use of serology might be help for suspecting HD. The laminated cyst wall and protoscolices are easy to be detected in histopathology specimens and are valuable in confirming diagnosis of HD. Surgical resection of cyst and the anthelmintic medications are the most common effective treatment of HD. Lately, HD rarely cause significance morbidities or mortalities in the present skilled hands and good health care.

\section{REFERENCES}

1. Eckert, J., \& Thompson, R. C. A. (2017). Historical aspects of echinococcosis. In Advances in parasitology (Vol. 95, pp. 1-64). Academic Press.

2. Moro, P., \& Schantz, P. M. (2009). Echinococcosis: a review. International journal of Infectious diseases, 13(2), 125-133.

3. Adewunmi, O. A., \& Basilingappa, H. M. (2004). Primary ovarian hydatid disease in the Kingdom of Saudi Arabia. Saudi Med J, 25(11), 1697-700.

4. Bektas, S., Erdogan, N. Y., \& Gurol Sahin, G. (2016). Clinicopathological Findings of Hydatid Cyst Disease: A Retrospective Analysis. Ann Clin Pathol, 4(3), 1071.

5. Giri, S., \& Parija, S. C. (2012). A review on diagnostic and preventive aspects of cystic echinococcosis and human cysticercosis. Tropical parasitology, 2(2), 99-108.

6. Alam A. A. (1999). Epidemiology of Hydatid Disease in Riyadh: A hospital-based study. Annals of Saudi Medicine, 19(5), 450-452.

7. Fahim, F., Al Salamah, S. M. (2007). Cystic Echinococcosis in Central Saudi Arabia: A 5 year experience. Turky Journal Gastroenterology, 18(1): 22-27.

8. Jastaniah, S., Malatani, T. S., Eshy, S. A., Al Shehry, M., Hamdi, J., Al Naami, M., ... \& Ghatani, S. S. (1997). Hydatid cyst disease (Echinococcus granulosus): Experience at Asir central hospital. Saudi Journal of Gastroenterology, 3(3), 140-143.

9. Malaika, S. S., Attayeb, A., Sulaimani, S., \& Reddy, J. J. (1981). Human echinococcosis in Saudi Arabia. Saudi Medical Journal, 2(2), 77-84.

10. Cancelo, M. J., Martín, M., \& Mendoza, N. (2012). Preoperative diagnosis of a breast hydatid cyst using fine-needle aspiration cytology: a case 
report and review of the literature. Journal of medical case reports, 6(1), 293.

11. Abdelrazeq, S. S., Al Ramadan, A. H., Dolachec, A. A., Abdulazez, M. M. (2019). Hydatid Cyst of the Qudrigeminal Cistern. A case report for unusual location with literature review. Romania Society of Neurosurgery, 23(2): 150-155.

12. Ma, X., Zhang, L., Wang, J., \& Luo, Y. (2019). Knowledge Domain and Emerging Trends on Echinococcosis Research: A Scientometric Analysis. International journal of environmental research and public health, 16(5), 842.

13. Yucel, Y., Seker, A., Eser, I., Ozgonul, A., Terzi, A., Gozeneli, O., ... \& Uzunkoy, A. (2015). Surgical treatment of hepatic hydatid cysts A retrospective analysis of 425 patients. Annali italiani di chirurgia, 86, 437-443.

14. Kohansal, M. H., Nourian, A., \& Bafandeh, S. (2015). Human Cystic Echinococcosis in Zanjan Area, Northwest Iran: A Retrospective Hospital Based Survey between 2007 and 2013. Iranian journal of public health, 44(9), 1277-1282.

15. Moradi, M., Rampisheh, Z., Roozbehani, M., \& Razmjou, E. (2019). A retrospective study of hydatid cysts in patients undergoing liver and lung surgery in Tehran, Iran. Heliyon, 5(6), e01897.

16. Rao, S. S., Mehra, B., \& Narang, R. (2012). The spectrum of hydatid disease in rural central India: An 11-year experience. Annals of tropical medicine and public health, 5(3), 225-230.

17. Ettorre, G. M., Vennarecci, G., Santoro, R., Laurenzi, A., Ceribelli, C., Di Cintio, A., ... \& Antonini, M. (2012). Giant hydatid cyst of the liver with a retroperitoneal growth: a case report. Journal of Medical Case Reports, 6(1), 298.

18. Dopchiz, M. C., Elissondo, M. C., Rossin, M. A., \& Denegri, G. (2007). Hydatidosis cases in one of mar Del plata city hospitals, Buenos Aires, Argentina. Revista da Sociedade Brasileira de Medicina Tropical, 40(6), 635-639.

19. Kurul, I. C., Topcu, S., Altinok, T., Yazici, U., Tastepe, I., Kaya, S., \& Cetin, G. (2002). Onestage operation for hydatid disease of lung and liver: principles of treatment. The Journal of thoracic and cardiovascular surgery, 124(6), 1212-1215.

20. Kayaalp, C., Dirican, A., \& Aydin, C. (2011). Primary subcutaneous hydatid cysts: a review of 22 cases. International Journal of Surgery, 9(2), 117-121.

21. Salehi, H., Boroujeni, K. S., \& Yaghoubi, S. (2019). Report of a hydatid cyst case with biceps brachii involvement. Advanced Biomedical Research, 8:23.

22. Kurz, K., Schwabegger, A., Schreieck, S., Zelger, B., Weiss, G., \& Bellmann-Weiler, R. (2019). Cystic echinococcosis in the thigh: a case report. Infection, 47(2), 323-329.
23. Yalagachin, G., \& Hegde, R. Extra Hepatic Primary Hydatid Diseases in Different Anatomic Location-A Case Series with Review of Literature. World J Surg Surgical Res. 2019; 2, 1094.

24. Papageorgiou, K. I., Kaniorou-Larai, M., \& Mathew, R. G. (2005). An unusual presentation of hydatid cyst within the soft tissues of the back: reinvestigation of the undiagnosed lung opacity. Respiratory medicine, 99(9), 1191-1194.

25. Babitha, F., Priya, P. V., \& Poothiode, U. (2015). Hydatid cyst of bone. Indian journal of medical microbiology, 33(3), 442-444.

26. Kothari, J., Lakhia, K., Solanki, P., Bansal, S., Boraniya, H., Pandya, H., \& Acharya, H. (2017). Invasive pericardial hydatid cyst: Excision of multiple huge cysts. Journal of the Saudi Heart Association, 29(1), 53-56.

27. Eshraghi, M., Shahmoradi, L., Ghoddoosi, M., \& Sadati, S. J. A. (2019). Diagnosis of Primary Hydatid Cyst of Thyroid Gland: A Case Report. Biomolecular concepts, 10(1), 106-110.

28. Rabehi, H., Bekhouche, R., \& Bendjaballah, A. (2018). A Huge Primary Hydatid Cyst of Uterus: A Case Report and Review of Literature. Journal of Universal Surgery, 6(2), 12.

29. Kuchimanchi, P. K., Chandrasekhar, P., Manasa, P. L., \& Koneru, G. (2019). Cystic echinococcus of head and neck: Anaphylactic dilemma and surgical considerations. Journal of Dr. NTR University of Health Sciences, 8(1), 62.

30. Benazzou, S., Arkha, Y., Derraz, S., El Ouahabi, A., \& El Khamlichi, A. (2010). Orbital hydatid cyst: review of 10 cases. Journal of CranioMaxillofacial Surgery, 38(4), 274-278.

31. Meera, M., Viruchali, T., \& Tanaya, Krunal, L. (2018). Primary Intraventricular Hydatid Cysts in a Child. Trop Parasitol, 8:47-49.

32. Mansfield, B. S., Pieton, K., \& Pather, S. (2019). Images in Tropical Medicine. Spinal cystic Echinococcosis. American Journal Trop Nyg, 100: 9-10.

33. Lv, H., Jiang, Y., Liu, G., Zhang, S., \& Peng, X. (2015). Surgical treatment of multiple hydatid cysts in the liver of a pediatric patient. The American journal of tropical medicine and hygiene, 92(3), 595-598.

34. Sparks, A. K., Conner, D. H., Neafie R. C. (1976). Disease Caused by Cestodes. In: Binford $\mathrm{CH}$, Conner DH, editors. Pathology of Tropical and Extraordinary Diseases: Armed Forces Institute of Pathology; 530.

35. Hui, M., Tandon, A., Prayaga, A. K., \& Patnaik, S. (2015). Isolated musculoskeletal hydatid disease: diagnosis on fine needle aspiration and cell block. Journal of parasitic diseases: official organ of the Indian Society for Parasitology, 39(2), 332-335.

36. Firpi, R. J., Lozada, L. R., Torres, E. A., Villamarzo, G., \& Lobera, A. (2014). Fine-needle 
aspiration diagnosis of hydatid cyst. Puerto Rico health sciences journal, 18(2):129-131.

37. Kammerer, W. S., \& Schantz, P. M. (1993). Echinococcal disease. Infectious disease clinics of North America, 7(3), 605-618.

38. Mohamadnejad, M., Kheyri, Z., Zamani, F., Sotoudeh, M., \& Al-Haddad, M. (2018). Pancreatic hydatid cyst diagnosed on EUS-guided FNA. VideoGIE: an official video. Journal of the American Society for Gastrointestinal Endoscopy, 4(8), 379-380.

39. Saha, A., Paul, U. K., \& Kumar, K. (2007). Diagnosis of primary hydatid cyst in thyroid by fine needle aspiration cytology. Journal of Cytology, 24(3), 137-139.
40. Velasco-Tirado, V., Alonso-Sardón, M., LopezBernus, A., Romero-Alegría, Á., Burguillo, F. J., Muro, A., ... Belhassen-García, M. (2018). Medical treatment of cystic echinococcosis: systematic review and meta-analysis. BMC infectious diseases, 18(1), 306.

41. Reza, H. A., Rreza, G., Nastaran, B., Mousa, M. (2019). Renal hydatic cyst; a rare infectious disease. Oxford Medical Case Reports, 4, 114116.

42. Belhassen-García, M., Romero-Alegria, A., Velasco-Tirado, V., Alonso-Sardón, M., LopezBernus, A., Alvela-Suarez, L., ... Pardo-Lledias, J. (2014). Study of hydatidosis-attributed mortality in endemic area. PloS one, 9(3), e91342. 